\title{
High-speed OTDM switching
}

Jepsen, Kim Stokholm; Mikkelsen, Benny; Clausen, Anders; Poulsen, Henrik Nørskov; Stubkjær, Kristian; Vaa, Michael

Published in:

Lasers and Electro-Optics, 1998. CLEO 98. Technical Digest. Summaries of papers presented at the Conference on

Link to article, DOI:

10.1109/CLEO.1998.675780

Publication date:

1998

Document Version

Publisher's PDF, also known as Version of record

Link back to DTU Orbit

Citation (APA):

Jepsen, K. S., Mikkelsen, B., Clausen, A., Poulsen, H. N., Stubkjær, K., \& Vaa, M. (1998). High-speed OTDM switching. In Lasers and Electro-Optics, 1998. CLEO 98. Technical Digest. Summaries of papers presented at the Conference on IEEE. https://doi.org/10.1109/CLEO.1998.675780

\section{General rights}

Copyright and moral rights for the publications made accessible in the public portal are retained by the authors and/or other copyright owners and it is a condition of accessing publications that users recognise and abide by the legal requirements associated with these rights.

- Users may download and print one copy of any publication from the public portal for the purpose of private study or research.

- You may not further distribute the material or use it for any profit-making activity or commercial gain

- You may freely distribute the URL identifying the publication in the public portal 


\section{CMA}

8:00 am-10:00 am

Room 100

\section{Optical TDM Systems}

Fred Heismann, Bell Labs/Lucent

Technologies, Presider

\section{CMA1 (Invited)}

8:00 am

High-speed OTDM switching

K.S. Jepsen, B. Mikkelsen, A.T. Clausen, H.N. Poulsen, K.E. Stubkjaer, M. Vaa, ${ }^{*}$ Center for Broadband Telecommunications, Department of Electromagnetic Systems, Technical University of Denmark, Building 348, DK-2800 Lyngby, Denmark; E-mail: kje@emi.dtu.dk

The speed limit for electronic switching and signal processing is currently $30-40 \mathrm{Gbits} / \mathrm{s}$, and thus optical techniques are needed in order to fully exploit the transmission bandwidth of optical fibers. Two complementary techniques for optical multiplexing exist, namely, optical time division multiplexing (OTDM) and wavelength division multiplexing (WDM). In both technologies the basic multiplexing and demultiplexing is carried out in the optical domain, but more advanced signal processing such as switching and regeneration can also be performed all-optically, i.e., without any optoelectronic conversion. WDM offers simple (passive) demultiplexing and routing of the optical channels, while, on the other hand, OTDM has transmission advantages such as simultaneous dispersion compensation and regeneration of all channels, reduced requirements to erbium-doped fiber amplifier gain flatness, and zero cross talk from fourwave mixing (FWM) or stimulated Raman scattering (SRS). As such, OTDM is well suited for "backbone" networks with long spans and few nodes but is also being considered for ultrahigh-speed local area networks (LANs). Several research groups and projects are currently investigating OTDM technology, ${ }^{1-5}$ and the state of the art currently allows point-point transmission followed by clock recovery and demultiplexing of up to $400-\mathrm{Gbit} / \mathrm{s}$ signals. ${ }^{4}$

Besides the techniques needed for pointpoint transmission, networking issues are also important in OTDM systems. As an example, consider WDM islands or OTDM rings, which are interconnected by an OTDM bus as shown in Fig. 1, which also lists the key functionalities needed in an OTDM network. At the network nodes, add/drop multiplexers (ADM) are placed for dropping (demultiplexing) channels from the bus and inserting new channels into the vacant timeslots. If the "add" channels originate from remote locations, an all-optical bit alignment and regeneration prior to adding is essential. In packet-switched networks, methods for dynamic header processing and routing and packet buffering are also needed.

High-speed all-optical signal processing/ switching such as clock recovery, demultiplexing, header processing, and buffering has been demonstrated at very high speeds using electroabsorption modulators, FWM in semicon-

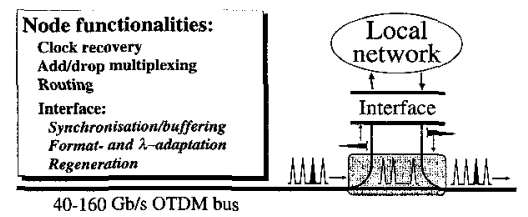

CMA1 Fig. 1. Top: OTDM bus used for longdistance interconnection of large regional networks with add/drop functionality.

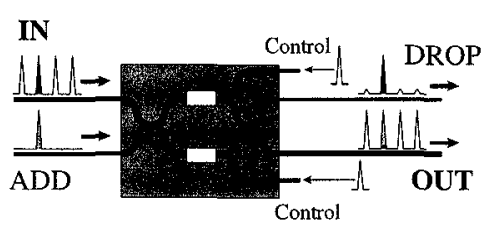

(a)

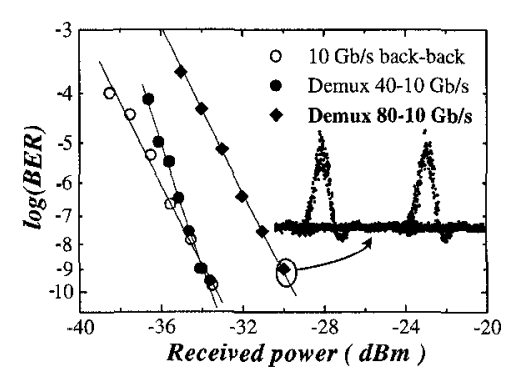

(b)

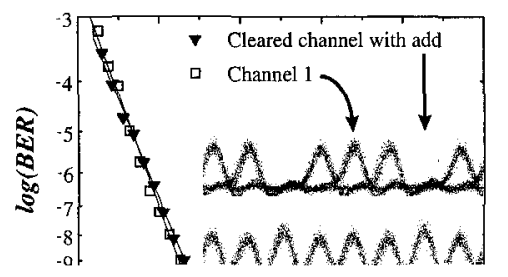

CMA1 Fig. 2. (a) One possible realization of add/drop multiplexer: SOA-based Mach-Zehnder interferometer (produced by ETH-Zürich), controlled by injection of short optical control pulses. (b) Examples of demultiplexing from 40 and 80 $\mathrm{Gbits} / \mathrm{s}$ to $10 \mathrm{Gbits} / \mathrm{s}$ using SOA-MZI. Inset shows output eye in the case of $80 \mathrm{Gbits} / \mathrm{s}$ demultiplexing. (c) Add multiplexing at $40 \mathrm{Gbits} / \mathrm{s}$ using SOA-MZI. Insets show cleared time slot and signal with a 10Gbit/s channel added in the cleared time slot. Biterror-rate (BER) curves are measured after demultiplexing using electroabsorption modulator.

ductor optical amplifiers, and a variety of NOLM schemes using both fiber- and semiconductor-based nonlinearities. Also, SOAs monolithically integrated in MachZehnder [Fig. 2(a)] or Michelson interferometers (SOA-MZI or SOA-MI) have proven to be a flexible solution as, e.g., add/drop multiplexers ${ }^{6}$ and regenerative wavelength and format converters with ultrahigh-speed capabilities. Using these structures, stable, bit-rate flexible demultiplexing can be performed as shown in Fig. 2(b). Moreover, the devices enable an efficient clearing of time slots for performing add multiplexing, as seen in Fig. 2(c).

A further example of the application of this type of device in the context of OTDM networking is given in Fig. 3. Here two all-optical SOA-MI wavelength converters (AOWCs) are cascaded to perform the tasks of bit alignment,

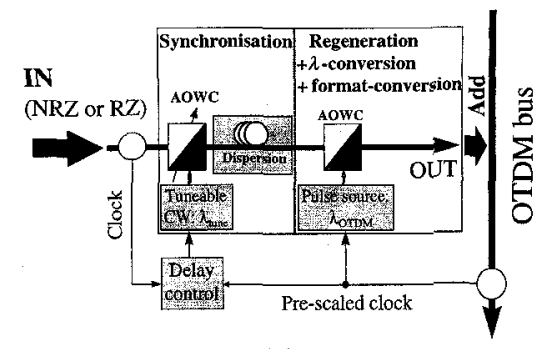

(a)

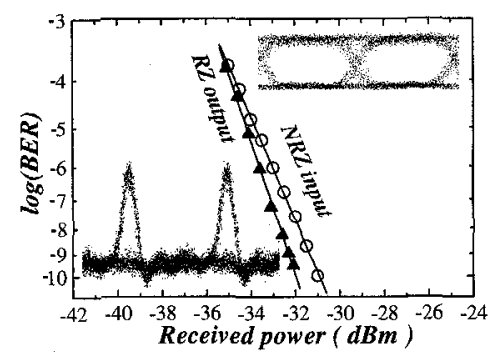

(b)

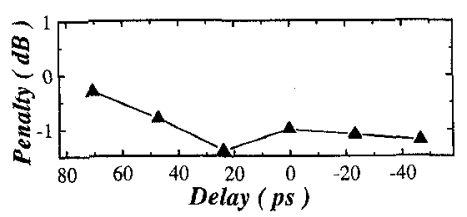

(c)

CMA1 Fig. 3. (a) Principle for performing synchronization, regeneration, and format and wavelength conversion. Incoming signal can be nonreturn to zero (NRZ) or return to zero (RZ), output signal is RZ. (b) Results for NRZ input signal (RZ output). A sensitivity improvement relative to input of $1 \mathrm{~dB}$ is seen. (c) Penalty vs. delay, controlled by adjusting wavelength at first AOWC. BER measurements in (b) are taken for 0-ps delay.

regeneration, wavelength conversion, and, if needed, format conversion, providing the interface from a local network to an OTDM bus. ${ }^{7}$

To summarize, OTDM continues to be of interest both for point-point transmission and as a networking technology for both LANs and long-distance transmission. Recent research has demonstrated enabling techniques for OTDM networks at high speeds, and in conclusion, OTDM is emerging as an attractive complement to WDM.

${ }^{*}$ DSC Communications, Lautrupbjerg 7-11, DK-2750 Ballerup, Denmark

1. R.A. Barry et al., IEEE J. Sel. Areas Commun. 14, 999 (1996).

2. S.-W. Seo et al., IEEE J. Sel. Areas Commun. 14, 1039 (1996).

3. A.D. Ellis et al., J. Lightwave Technol. 13, 761 (1995).

4. S. Kawanishi, in OECC'97 Technical Digest (1997), paper 8A1-3.

5. M. Eiselt et al., J. Lightwave Technol. 13, 2099 (1995).

6. R. Hess et al., in Optical Amplifiers and Their Applications, Vol. XVI of OSA Trends in Optics and Photonics Series (Optical Society of America, Washington, D.C., 1997), paper WA3.

7. K. Jepsen et al., in Proceedings of ECOC'97 (1996), paper Th3C8. 